\title{
광전력 진폭변조와 $\mathrm{ICA}$ 를 이용한 $\mathrm{PPG}$ 신호의 동잡음 제거 필터 설계
}

\author{
이주원* · 이병로**
}

Design of Filter to remove motion artifacts of PPG signal using Amplitude Modulation of Optical Power and Independent Components Analysis

Ju-won Lee* · Byoung-Ro Lee**

이 논문은 2012년도 경남과학기술대학교 지원으로 수행되었음

요 약

최근 IT+BT 융합 기술로 건강관리 및 응급의료 등을 위하여 U-헬스케어 단말 장치가 개발되고 상품화가 되고 있 다. 이 단말기에서 측정하는 생체 신호들은 심전도, 체온, 산소포화도, 심박수, 호흡 등이며, 특히 이들 신호 중에 광 용적맥파(PPG) 신호는 산소포화도와 심박수, 말초혈관 탄성도 등을 측정함에 있어 매우 중요한 신호이다. 그러나 이 PPG 신호는 환자 또는 사용자의 움직임에 따라 발생하는 동잡음의 영향에 의해 그 정밀도가 저하된다. 따라서 본 연구에서는 이러한 동잡음을 제거하기 위한 광변조 기법과 ICA 기법을 제안한다. 제안된 기법의 성능을 분석하 기 위해 다양한 잡음을 인위적으로 가하여 실험하였으며, 실험 결과를 분석한 결과에서 제안된 기법이 기존의 적응 필터법 보다 우수한 성능을 보였다.

\section{ABSTRACT}

Recently, u-healthcare device is developed and commercialized for healthcare management and emergency medical. The kinds of the measurable biomedical signals on the device are electrocardiogram, skin temperature, pulse oxygen, heart rate, respiration, etc. Specially, the photoplethysmograph(PPG) signal of these signals is the important signal in measuring oxygen, heart rate and peripheral vascular compliance. The accuracy of PPG signal reduce from influence of the motion artifacts that generated from the movements of user or patient. Therefore, this study suggests a new method to remove the motion artifact that is using optical power modulation and ICA(Independent Component Analysis). For analyzing the proposed method, we used variety of noises made by artificially. In the results of experiments, the proposed method showed good performances than an adaptive filter.

$$
\text { 키워드 }
$$

$\mathrm{U}$-헬스케어, 광용적맥파, 동잡음, 독립성분분석, 적응필터

Key word

u-healthcare, photoplethysmograph(PPG), motion artifacts, Independent Component Analysis, adaptive filter

\footnotetext{
* 종신회원 : 안동과학대학교 의료공학과

** 종신회원 : 경남과학기술대학교 전자공학과
}

접수일자 : 2012. 11. 28

심사완료일자 : 2012. 12. 26

\section{Open Access http://dx.doi.org/10.6109/jkiice.2013.17.3.691}

(c)This is an Open Access article distributed under the terms of the Creative Commons Attribution Non-Commercial License(http://creativecommons.org/li-censes/by-nc/3.0/) which permits unrestricted non-commercial use, distribution, and reproduction in any medium, provided the original work is properly cited.

Copyright $(\mathbb{C}$ The Korea Institute of Information and Communication Engineering. 


\section{I. 서 론}

개인의 건강관리 및 응급의료의 긴급한 상황을 효율 적으로 처리하기 위해 $\mathrm{u}$-헬스케어 단말 장치가 개발되 고 상품화가 되고 있다[1]. 이 헬스케어 단말기에서 측 정할 수 있는 생체신호는 대표적으로 심전도, 심박수, 광용적 맥파(PPG: Pothople -thysmo graphy), 혈압, 체온, 산소포화도, 호흡 등이 있으며, 이들 신호 중에 광용적 맥파인 PPG 신호는 심혈관 질환 및 혈관 탄성도, 산소 포화도 등에 관련된 질병을 분석하는데 사용되고 있어 가장 많이 사용한다. 이들 신호 중에 PPG 신호는 말초 혈관 혈류량의 변화에 따른 조직에서의 광흡수도 변화 를 측정하는 것으로 심박수, 혈중 산소포화도, 혈압, 동 맥 탄성도 등의 중요한 생체 정보를 모니터링 할 수 있 다. 그러나 PPG 신호 측정에 있어 환자의 움직임에 따 라 그 성능이 저하되어 부정확한 심박수 및 산소포화도 를 제공하는 문제점을 갖고 있다. 이 문제점은 PPG 신 호의 주파수 대역이 환자의 움직임으로부터 발생되는 동잡음 주파수 대역과 겹쳐 있어 일반적인 신호 필터로 잡음을 제거가 어렵다[2]-[7]. 이러한 문제점을 해결하 기 위해 최근에는 PPG 신호를 주기 신호로 가정한 앙 상블 필터 법[3]과 가속도 센서를 기반한 적응 필터 법 [4][5] 등이 연구되었다. 이러한 기법들의 동잡음 제거 성능이 개선되었으나, 아직까지도 그 성능이 만족스 럽지 못하고, 가속도 센서 추가로 제품 단가가 높아지 는 단점을 가지고 있다. 따라서 본 연구에서는 광 전력 진폭 변조기법과 독립 성분 분석법을 이용한 PPG 신 호 추출 기법을 제안하고, 그 성능을 분석하기 위해 동 잡음을 인위적으로 센서에 가하여 성능을 평가하고 그 결과를 제시 하였다.

\section{ㅍ. AM변조와 ICA를 이용한 $P P G$ 신호처리}

일반적으로 PPG 신호는 그림 1 과 같이 $960[\mathrm{~nm}]$ 파장 대역의 적외선 또는 $640[\mathrm{~nm}]$ 파장 대역의 적색 광 $T_{P}(t)$ 를 인체에 조사한 후, 반사 또는 투과된 광 $S(t)$ 을 수광 센서(photosensor)로 측정할 있으며, 이 수광 신호는 식 (1)과 같이 Beer-Lambert 법칙[7]을 따른다.

$$
S(t)=T_{p}(t) e^{-\Delta d}=T_{p}(t) e^{-\left(\Delta d_{A}+\Delta d_{\mathfrak{A}}+\Delta d_{\mathbb{s}}+\Delta A_{N}\right)}
$$

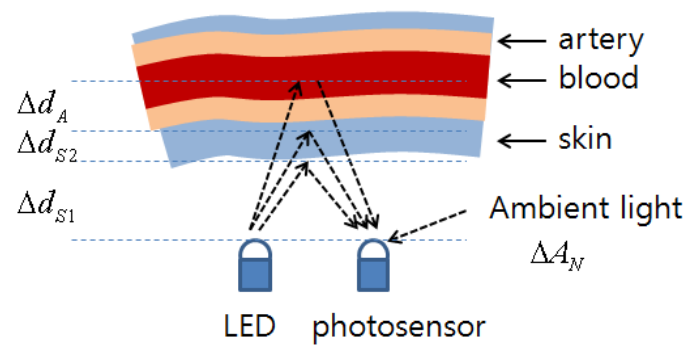

그림 1. PPG 신호의 측정 원리

Fig. 1 Measuring principle of the PPG signal

식(1)에서 $\Delta d$ 는 혈관 속에 흐르는 혈류에 의한 광원 흡수의 변화 $\Delta d_{A}$ 와 피부 표면과 광원사이의 거리 변화 $\Delta d_{S 1}$ 그리고 피부 내부와 광원사이의 거리 변화, 외부 광 원 변화 $\Delta A_{N}$ 등이 모두 포함된 변화분이다. 따라서 심 박수 측정 또는 혈관 탄성도 측정에 필요한 PPG 신호 $P(t)$ 는 식(2)와 같으며, 식 (1)의 나머지 변화 성분인 $\Delta d_{S 1}, \Delta A_{N}$ 은 모두 잡음으로 간주할 수 있다.

$$
P(t)=T_{P} e^{-\Delta d_{A}}
$$

이와 같이 수광 센서로부터 측정된 신호 $S(t)$ 에는 환 자의 움직임에 따른 잡음과 외부 잡음 등이 혼입되어 PPG 신호 $P(t)$ 를 추출하기가 어렵다. 이러한 문제점을 해결하기 위해 현재의 의료기기는 높은 주파수로 LED 를 구동시켜 주변 광원의 영향을 최소화하고 있다. 그러 나 환자의 움직임으로 발생되는 동잡음(motion artifacts) 은 동잡음 주파수 대역 $(0.01-10[\mathrm{~Hz}])$ 이 PPG 신호의 주파 수 대역 $(0.05-8[\mathrm{~Hz}])$ 과 겹쳐 있어 일반적인 필터로는 동 잡음을 제거하기가 어렵다[3]-[9]. 따라서 본 연구에서 는 식(1)의 특징으로부터 식(3)과 같이 광원 전력 세기에 따라 광 도달 거리와 수광량이 다르다고 가정하고, 그림 2 와 같이 잡음이 없는 PPG 신호를 추출하기 위해 LED 광 세기를 진폭변조(Amplitude Modulation)하여 손가락 에 투광시킨 다음, 반사되어 오는 수광 신호를 $N$ 개 채널 로 분리하여 측정하도록 하였다.

$$
\Delta d=-\left(\log _{e} S(t)-\log _{e} T p(t)\right)
$$




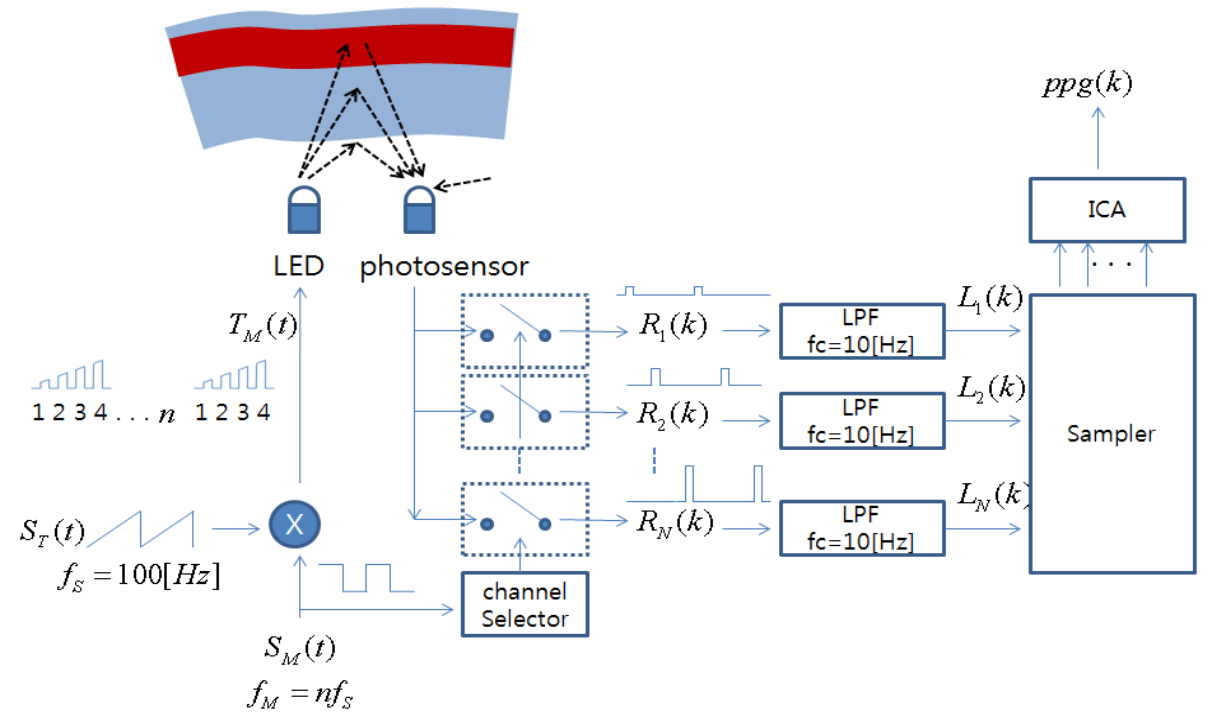

그림 2. 동잡음 제거를 위한 제안된 PPG 신호처리

Fig. 2 PPG signal processing to reject motion artifacts

그리고 측정된 $N$ 개 의 채널 신호는 PPG 신호만을 추 출하기 위해 저역통과 필터를 거쳐 신호분리 성능이 우 수한 독립성분분석(ICA)에 입력하고 $\mathrm{ICA}$ 는 각각의 $\mathrm{PPG}$ 신호와 잡음신호를 분리하도록 처리하였다. 즉, 제안된 방법은 그림 2 와 같이 광원의 전력이 세기에 따라 외부 광에 의한 잡음, 피부에 의한 반사광, 피부 내부로부터 반사되어 오는 반사광, 혈류의 흐름에 의한 PPG 신호 등 을 측정할 수 있다는 것이다. 여기서 $\mathrm{AM}$ 변조는 식(4)와 같이 PPG 신호의 샘플링 주파수 $f_{s}$ 와 동일한 톱니파 신 호 $S_{T}(t)$ (식(5))와 광전력에 따라 분리하고자하는 채널 수 $N$ 과 동일한 주파수 $f_{m}=N f_{s}$ 를 가진 펄스 신호 $S_{M}(t)$ (식(6))와 곱하여 $\mathrm{AM}$ 변조된 신호 $T_{M}(t)$ 를 $\mathrm{LED}$ 구동 전 압으로 사용하였다.

$$
\begin{aligned}
& T_{M}(t)=V_{f} S_{T}(t) S_{M}(t) \\
& V_{f}: L E D \text { 순방향최대전압 } \\
& S_{T}(t)=\left\{\begin{array}{ll}
t, & 0 \leq t \leq T_{W} \\
0, & \text { otherwise }
\end{array}, \quad T_{W}=1 / f_{S}\right. \\
& S_{M}(t)=\left\{\begin{array}{ll}
1, & 0 \leq t \leq T_{P} / 2 \\
0, & \text { otherwise }
\end{array}, T_{P}=1 /\left(N f_{S}\right)\right.
\end{aligned}
$$

식(4)의 AM 변조기의 출력 순서에 따라 다 채널로 수 광 신호를 분리하기 위해서 $\mathrm{AM}$ 변조의 주기 신호의 상 승 에지(edge)와 동기화로 각각의 채널로 분리하였다. 이때 출력된 신호는 $R_{1}(k), R_{2}(k), \cdots, R_{N}(k)$ 이고, 각 $R_{n}(k)$ 는 $1 /\left(n f_{s}\right)$ 만큼 위상지연이 발생한다. 이 위상지 연은 ICA 신호처리과정에서 부정확한 신호 분리를 야기 하기 때문에 동일한 위상의 샘플링 값을 가져야 한다. 따 라서 위상지연의 문제를 해결하기 위해 $10[\mathrm{~Hz}]$ 차단주 파수를 가진 4 차 FIR 구조의 저역통과 필터를 통과 시킨 후, $f_{S}=100[\mathrm{~Hz}]$ 의 주파수로 샘플링 과정을 거쳐 위상지 연을 제거하도록 하였다. 샘플링과 필터링된 각 채널의 신호인 $L_{1}(k), L_{2}(k), \ldots, L_{N}(k)$ 는 ICA의 입력 벡터 $\boldsymbol{x}(n)$ 로 사용되며, 미지의 혼합 행렬 $\boldsymbol{A}$, 원 신호 벡터를 $\boldsymbol{y}(n)$ 이라 가정하여, 식(7) (9)로부터 PPG신호와 잡음신호, 외부 광 신호를 분리하도록 하였다.

$$
\begin{aligned}
& \boldsymbol{x}(n)=\left[L_{1}(n) L_{2}(n) \ldots L_{N}(n)\right]^{T} \\
& \boldsymbol{x}(n)=\boldsymbol{A} \boldsymbol{y}(n) \\
& \boldsymbol{P}(t)=\boldsymbol{y}(n)=\boldsymbol{W} \boldsymbol{x}(n),
\end{aligned}
$$


식(8)에서 신호의 분리 행렬 $W$ 는

$$
W \approx A^{-1}
$$

으로 정의할 수 있기 때문에 보다 정확한 신호 분리를 위 해 반복적인 학습을 통하여 최적의 $W$ 를 구해야한다. 따 라서 본 연구에서는 식 (11)과 같이 일반적으로 사용되 는 Infomax 학습법[10]을 사용하였으며, 이 학습법은 가 장 빠른 학습 속도의 무감독 학습법으로 신호 내에 포함 된 상호정보의 엔트로피를 최대화하여 $W$ 를 구하는 기 법이다.

$$
\begin{aligned}
& W(n+1)=W(n)+\lambda\left(\boldsymbol{I}-\tanh (\boldsymbol{y}) \boldsymbol{y}^{T}\right) \boldsymbol{W}(n) \\
& \lambda: \text { 학습 상수 }
\end{aligned}
$$

이와 같이 이 학습법을 통하여 최적의 $W$ 를 구한 다 음, 동잡음의 영향이 최소화된 PPG 신호 $P(t)$ 를 식(9)로 부터 구할 수 있다.

\section{III. 실험 및 고찰}

본 논문에서 제안한 기법의 성능을 평가하기 위해 다 양한 잡음(동잡음이 없을때, 두드림, 손가락 구부림, 자 유 움직임)들을 인위적으로 가하여 대표적인 적응필터 와 성능을 비교하였다. 성능평가 실험을 위하여 Atmel사 의 마이크로프로세서인 Atmega32-16MHz, 4비트 D/A 변환기, $920[\mathrm{~nm}]$ 파장의 적외선 $\mathrm{LED}$, 포토트랜지스터 등을 이용하여 그림 3 과 같이 광변조회로 설계 하였다. 설계된 광 변조회로를 그림 4 와 같이 구현하였다. 구현 된 회로에서는 광 전력변조 기능을 Codevison 컴파일러 를 통해 $\mathrm{C}$ 언어로 적성하여 $\mathrm{DA}$ 변환기로 출력(그림 5)하 게 하고 $\mathrm{CPU}$ 내부의 $10 \mathrm{bit} \mathrm{AD}$ 변환기를 통하여 각 채널 별 신호를 샘플링하고 직류성분 $(0.5 \mathrm{~Hz}$ 이하)을 제거한 다음, $\mathrm{RS} 232$ 의 $19200[\mathrm{bps}]$ 속도로 $\mathrm{PC}$ 에 측정 데이터를 전송하였다.

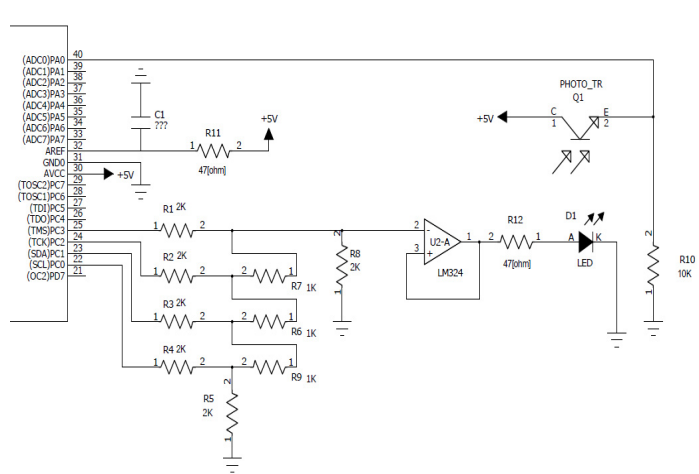

그림 3. 광전력 $\mathrm{AM}$ 변조 $\mathrm{PPG}$ 신호처리 회로 Fig. 3 PPG signal processing circuit Using Amplitude Modulation of Optical Power

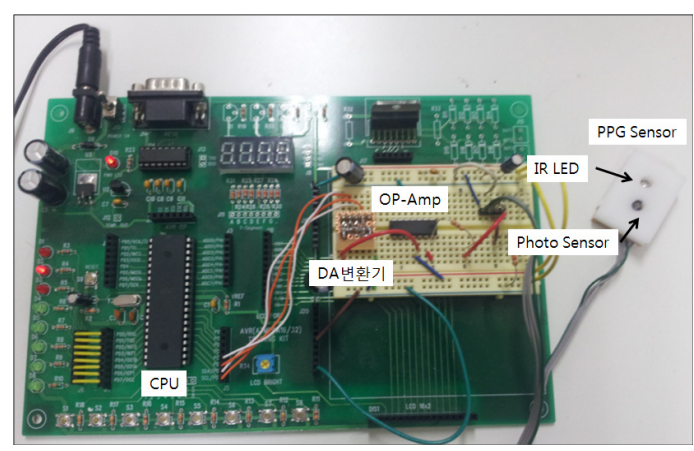

그림 4. 구현된 PPG 신호처리부

Fig. 4 Implemented PPG signal processing unit

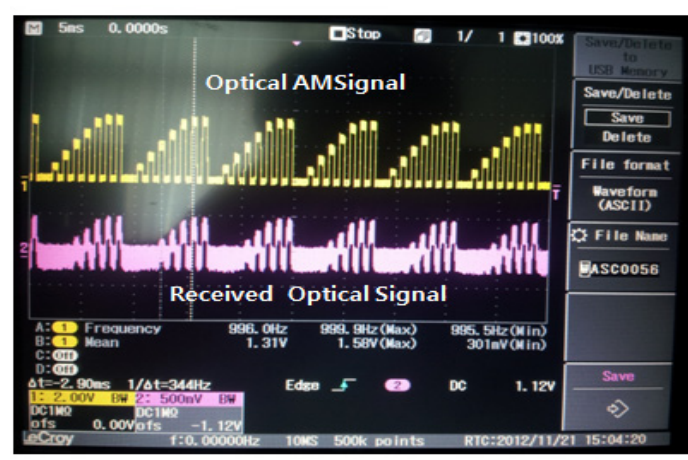

그림 5. 관측된 광 $\mathrm{AM}$ 신호와 수광 신호

Fig. 5 Observed Optical AM signal and received signal from photo sensor 
그리고 $\mathrm{PC}$ 에서는 데이터를 Matlab에서 작성된 ICA 알고리즘에 입력하여 필터링 성능을 분석하였다. 이때 설정된 학습 상수 및 학습 횟수는 0.001 과 100 회이다. 실 험에서 사용된 채널수와 광변조 주파수는 4 개와 $400[\mathrm{~Hz}]$ 로 설정하였고, 수광부의 각 채널에 사용된 LPF 필터는 FIR구조의 $10[\mathrm{~Hz}]$ 차단주파수를 가진 4-차 버터 워스 필터를 사용하였다. 특히, 광변조에서의 광 전력의 세기는 5[V] 참조전압을 가진 4비트 DA변환기의 출력 전압을 0.3[V], 0.67[V], $1.32\{\mathrm{~V}\}, 2.64[\mathrm{~V}]$ 로 설정하여 실 험하였다. 실험 결과에서 동잡음이 없을 때, 각 채널에 따른 출력 전압을 그림 6에 나타내었으며, 이 결과로부 터 식(3)처럼 광 전력에 따라 수광 신호의 크기가 다르고 피부의 깊이에 따라 다르다는 것을 알 수 있었다. 특히, 채널 2 의 신호에서는 피부 표면반사에 의한 동잡음 신호 임을 알 수 있었다. 그리고 동잡음의 유무에 따른 기법 의 출력을 그림 7과 8에 나타내었다. 이 결과에서 그림 7 은 동잡음이 없을 때 ICA 출력을 나타낸 결과로서 채널 1 의 신호가 원 신호(Original signal)와 유사함을 육안으 로 알 수 있었다.

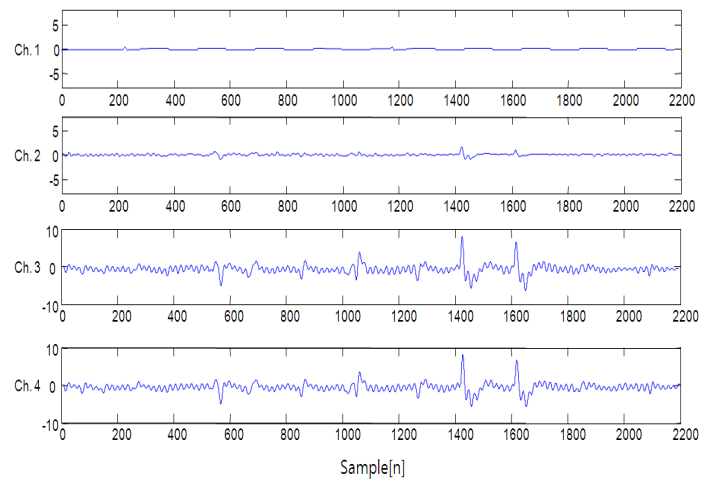

그림 6. 광변조 전력에 따른 동잡음이 포함된 수광 신호 Fig. 6 Received signals with motion artifact based on optical modulation power

그리고 동잡음하에 제안된 기법의 성능 분석하기위 해 센서를 착용하고 있는 손가락에 다양한 동잡음(두드 림, 손가락 구부리기, 손가락 상하좌우로 움직임)을 1 2 회 정도로 인위적으로 가하여 적응필터(학습 상수 $=$ 0.001 , 필터 차수 $=32$ 차)와 $\mathrm{ICA}$ 의 출력 신호를 그림 8 에 나타내었으며, ICA 출력 중의 3 번 신호와 적응필터의
신호에 대하여 주파수 분석한 결과를 그림 9에 나타내 었다.

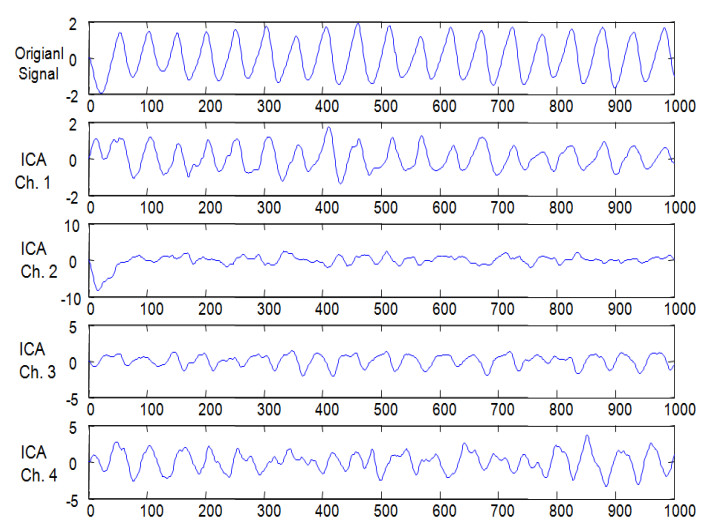

그림 7. 동잡음이 없을 때 ICA 필터의 출력 Fig. 7 Outputs of ICA filter without motion artifacts.

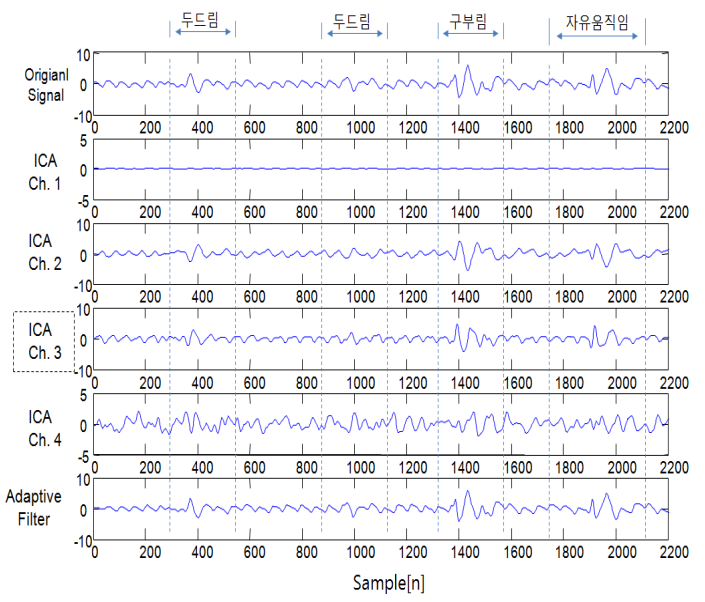

그림 8. 다양한 동잡음에 따른 제안된 기법(ICA)의 출력

Fig. 8 Outputs of proposed method from variety of motion source.

그림 8의 결과에서 제안된 기법의 출력이 적응필터 보다 맥파의 신호 추출이 양호함을 알 수 있었다. 그림 9 에서는 동잡음이 없는 구간의 PPG 신호와 비교한 결과 를 나타내었으며, 이 결과에서 제안된 기법이 적응필터 보다 우수함을 알 수 있었다. 


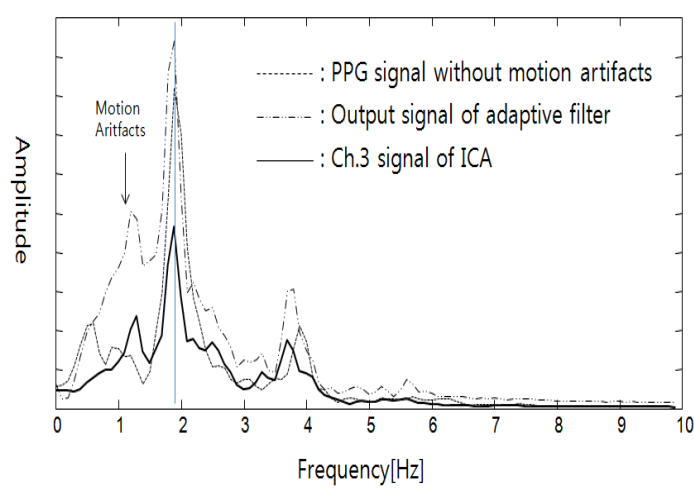

그림 9. 주파수 분석

Fig. 9 Frequency analysis.

\section{IV. 결 론}

본 논문에서는 $\mathrm{u}$-헬스케어 단말기의 측정 신호 중에 하나인 PPG 신호 처리에 관한 연구로서 PPG 신호 처 리의 문제점인 동잡음 제거하기위해 광 변조와 ICA 기 법을 이용한 신호처리 기법을 제안하였다. 제안된 알 고리즘의 성능 분석을 위해 인위적으로 다양한 움직 임을 주어 적응필터링법과 성능을 비교 실험하고 평 가하였다. 이 결과, 본 논문에서 제안한 동잡음 제거 알 고리즘이 적응필터 보다 우수한 성능을 가짐을 확인 할 수 있었다. 향후, 본 연구에서 육안으로 최적의 ICA 출력 채널을 선택하는 방법 대신 최적의 신호 채널을 추출하는 알고리즘에 관하여 연구가 진행되어야 할 것이다. 그리고 최적의 채널 선택 알고리즘과 제안된 알고리즘을 헬스케어 단말기에 적용한다면 환자의 움 직임에서도 보다 정확한 신호 측정과 분석이 가능할 것으로 사료된다.

\section{참고문헌}

[1] V. Rialle, F. Dunchene, N. Noury, L. Bajolle, and J. Demongeot, "Health Smart Home : Information Technology for patients," Telemedicine and Journal and e-Health, vol. 8, no. 4, pp. 395-409, 2002.
[2] J. Lee, W. Jung, I. Kang, Y. Kim, G. Lee, "Design of filter to reject motion artifact of pulse oximetry," Computer Standards and Interfaces vol. 26 no. 3, pp. 241 - 249, 2004.

[ 3 ] H. W. Lee, J. W. Lee, W. G. Jung, and G. K. Lee, "The Periodic Moving Average Filter for Removing Motion Artifacts from PPG Signals," International Journal of Control, Automation, and Systems, vol. 5, no. 6, pp. 701-706, 2007.

[4] W. Y. Chung, S. Bhardwaj, A. Purwar, D. S. Lee, and R. Myllylae, "A fusion health monitoring using ECG and accelerometer sensors for elderly persons at home", Proceedings of the 29th Annual International Conference of the IEEE Engineering in Medicine and Biology Society, Lyon, pp. 3818-3821, 2007.

[ 5 ] H. H. Asada, H. H. Jiang, and P. Gibbs, "Active noise cancellation using MEMS accelerometers for motion-tolerant wearable bio-sensors," Proceedings of the 26th Annual International Conference of the IEEE Engineering in Medicine and Biology Society, San Francisco. CA, pp. 2157-2160, 2004.

[6] J. W. Lee and B. R. Lee, "Heart rate estimation based on PPG signal and histogram filter for mobile healthcare," International Journal of Maritime Information and Communication Sciences, vol. 8, no. 1, pp. 112-115, 2010.

[7] K. K. Tremper and S. J. Baker, Pulse oximetry and oxygen transform, in Purse Oximetry, Berlin: Springer-Verlag, 1996.

[ 8 ] J. W. Lee, J. H. Nam, "Design of filter to reject motion artifacts of PPG signal by Using Two Photosensors," $J$. Inf. Commun. Converg. Eng.. vol. 10, no. 1, pp. 91-95, 2012.

[9] 이한욱 외 3, "생체 정보 감시 장치를 위한 광변조 기 법의 PPG 신호처리," 의공학회지, vol. 30, no. 6, pp. 503-509, 2009.

[10] A. J. Bell and T. J. Sejnowski, "An informationmaximization approach to blind separation and blind deconvolution," Neural Computation, vo1. 7, pp.1129-1159, 1995. 


\section{저자소개}

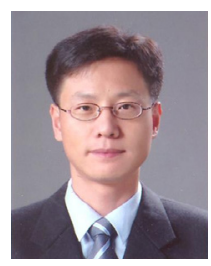

이주원(Ju-Won Lee)

2008년 현재 :안동과학대학

의료공학과 조교수

※관심분야: 유비쿼터스 헬스케어,

의용전자, 인공지능, $\mathrm{HCI}$

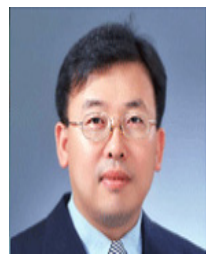

이병로(Byeong-Ro Lee)

현재: 경남과학기술대학교

전자공학과 교수

※관심분야: 신호처리, 전자응용. 